\title{
REASONS AND IMPOSSIBILITY
}

\author{
Bart Streumer \\ b.streumer@rug.nl \\ Philosophical Studies 136 (2007): 351-384 \\ Published version available here: \\ http://dx.doi.org/10.1007/s11098-005-4282-1
}

\section{Abstract:}

Many philosophers claim that it cannot be the case that a person ought to perform an action if this person cannot perform this action. However, most of these philosophers do not give arguments for the truth of this claim. In this paper, I argue that it is plausible to interpret this claim in such a way that it is entailed by the claim that there cannot be a reason for a person to perform an action if it is impossible that this person will perform this action. I then give three arguments for the truth of the latter claim, which are also arguments for the truth of the former claim as I interpret it. 


\section{REASONS AND IMPOSSIBILITY}

Many philosophers believe that the following claim is true:

(O) It cannot be the case that a person ought to perform an action if this person cannot perform this action. ${ }^{1}$

According to other philosophers, however, this claim is false. ${ }^{2}$ And most philosophers who think that this claim is true do not give arguments for its truth. ${ }^{3}$ Instead, these philosophers often merely assume that $(\mathrm{O})$ is true, or merely argue that $(\mathrm{O})$ has not been shown to be false. $^{4}$

\footnotetext{
${ }^{1}$ Immanuel Kant is often taken to be the first philosopher to endorse (O) (see Kant 1781/87, A548/B576, 1788, 5: 30 and 5: 36, and 1793, 8: 287; for discussion of Kant's views on (O), see Stern 2004). However, the fifth-century thinker Pelagius also endorsed a version of (O) (see Matthews 1998), and so did Thomas Hobbes (see Hobbes 1651, 97). Later philosophers who endorse (O) include Broad 1952, Hare 1963, 51-61, Feldman 1986, Zimmerman 1996, and Haji 1998 and 2002. As I shall argue in section 2 below, (O) can be interpreted in different ways, and these philosophers do not all interpret it in the same way.

${ }^{2}$ Pelagius' endorsement of (O) was denounced as heresy by Augustine (see Matthews 1998). Contemporary philosophers who reject (O) include Stocker 1971, White 1975, 147-57, Kekes 1984, Sinnott-Armstrong 1984, Sinnott-Armstrong 1985, Fischer 1999, 124-25, Fischer 2003, 248-49, Saka 2000 and Kramer 2004. Like those who endorse (O), these philosophers do not all interpret (O) in the same way.

${ }^{3}$ As is noted by Frankena 1950, 157, and Stocker 1971, 303. There are three main exceptions to this. First, some philosophers defend $(\mathrm{O})$ by claiming that it is inappropriate to blame a person for failing to perform an action if this person cannot perform this action, or by claiming that it is pointless to tell a person that he or she ought to perform an action if this person cannot perform this action. However, these claims fall short of being arguments for the truth of $(\mathrm{O})$, since the first is about blame rather than about whether or not this person ought to perform this action, and since the second is about the point of telling a person that he or she ought to perform an action rather than about whether
} 
In this paper, I shall try to do more than this. I shall argue that it is plausible to interpret $(\mathrm{O})$ as having the same truth-conditions as the following claim:

(M) It cannot be the case that there is most reason for a person to perform an action if it is impossible that this person will perform this action. ${ }^{5}$

I shall argue that $(\mathrm{M})$ is entailed by the following claim:

(R) There cannot be a reason for a person to perform an action if it is impossible that this person will perform this action.

And I shall give three arguments for the truth of (R). Since (R) entails (M), and since (M) has the same truth-conditions as $(\mathrm{O})$ as I interpret it, these three arguments are also arguments for the truth of $(\mathrm{O})$ as I interpret it.

This paper consists of seven sections. In section 1, I show why it matters whether (O) is true. In section 2 , I argue that it is plausible to interpret $(\mathrm{O})$ as having the same truth-

or not this person actually ought to perform this action (see Sinnott-Armstrong 1984, 250-1, and Stern 2004, 46-50). Second, some philosophers defend (O) by giving examples of actions that a person cannot perform, and of which it therefore does not seem to be the case that this person ought to perform them (see Copp 1997, 445-6, and Schnall 2001, 338-9). However, these philosophers do not use these examples to set up a systematic argument for the truth of $(\mathrm{O})$, and do not consider objections that can be made to such an argument. Third, $(\mathrm{O})$ is entailed by the analyses of moral obligation that are given by Hare 1963, Feldman 1986 and Zimmerman 1996, and Hare, Feldman and Zimmerman do give arguments for their analyses of moral obligation. However, these arguments are not arguments for the truth of $(\mathrm{O})$ independently of these analyses.

${ }^{4}$ For excellent discussions of why $(\mathrm{O})$ has not been shown to be false, see Zimmerman 1996, 79113, and Haji 2002, 43-45, 77-84, 211-20.

${ }^{5}$ I use the term 'reason' to mean pro tanto normative reason, and I treat normative claims - that is, claims that incorporate terms like 'reason', 'most reason', 'ought', 'obligation' and 'good' in certain ways - as having truth-conditions. Of course, it is controversial whether such claims should be treated in this way, but I have no space to defend this treatment here. 
conditions as (M), and I show that (M) is entailed by (R). In sections 3, 4 and 5, I give my three arguments for the truth of (R). In section 6, I defend (R) against two objections. And in section 7, I argue that, if my arguments are sound, $(\mathrm{O})$ is true in a sense that matters.

\section{Why it matters whether $(0)$ is true}

Many philosophers give arguments that appeal to $(\mathrm{O})$. The main reason why it matters whether $(\mathrm{O})$ is true is that it matters whether the conclusions of these arguments are true.

One argument that appeals to $(\mathrm{O})$ concerns the possibility of moral dilemmas. According to some philosophers, there can be moral dilemmas of the following form: ${ }^{6}$

(1) Person P ought to perform action A.

(2) Person P ought to perform action B.

(3) Person $\mathrm{P}$ cannot both perform action $\mathrm{A}$ and perform action $\mathrm{B} .^{7}$

According to other philosophers, there cannot be moral dilemmas of this form. One argument that these philosophers give for this conclusion is this. ${ }^{8}$ Suppose that the following principle

\footnotetext{
${ }^{6}$ See Lemmon 1962, 148-50, Williams 1973, 171, van Fraassen 1973, 8, and Marcus 1980, 122. It is not entirely clear whether these philosophers take 'ought' to be an overall term (which is how I use the term 'ought' in this paper) or a pro tanto term (which is how I use the term 'reason' in this paper). Opponents of these philosophers' views often take them to be using 'ought' as an overall term, perhaps because these philosophers suggest that the existence of moral dilemmas causes trouble for deontic logic, which can only be true if that they take 'ought' to be the overall 'ought' of deontic logic (see Brink 1994, 224 and 247 n. 39, and Zimmerman 1996, 217-19).

${ }^{7}$ Strictly, we should add to this that person $\mathrm{P}$ can perform action $\mathrm{A}$ and that person $\mathrm{P}$ can perform action $\mathrm{B}$, since person $\mathrm{P}$ cannot be said to be in a moral dilemma if he or she cannot perform action $\mathrm{A}$, or if he or she cannot perform action B (see Brink 1994, 224).

${ }^{8}$ See McConnell 1978, 271-72, Donagan 1984, 297, Gowans 1987, 20-21, Brink 1994, 227-28, and Zimmerman 1996, 212-3.
} 
of agglomeration is true:

(A) If a person ought to perform action $\mathrm{X}$ and this person ought to perform action $\mathrm{Y}$, then this person ought to both perform action $\mathrm{X}$ and perform action $\mathrm{Y}$.

(1), (2) and (A) together entail:

(4) Person P ought to both perform action A and perform action B.

Now suppose that (O) is true. (4) and (O) together entail:

(5) Person $\mathrm{P}$ can both perform action $\mathrm{A}$ and perform action $\mathrm{B}$.

And (5) contradicts (3).

According to the philosophers who give this argument, $(A)$ and $(\mathrm{O})$ are each more plausible than the claim that there can be moral dilemmas of the form exemplified by (1), (2) and (3). Therefore, according to these philosophers, we should conclude that there cannot be moral dilemmas of this form. But other philosophers disagree, and reject either (A) or (O). ${ }^{9}$

Another argument that appeals to $(\mathrm{O})$ concerns the compatibility of determinism with claims about what we ought to do. Given that a possible world is nomologically and historically accessible if and only if its laws of nature and its past are the same as those of the actual world, determinism can be formulated as follows:

(D) There is no nomologically and historically accessible possible world the future of which is different from the future of the actual world.

\footnotetext{
${ }^{9}$ For example, Lemmon 1962, 150 n. 8, rejects (O). Williams 1973, 181-82, and Marcus 1980, 134, reject (A). For a possible reason to reject (A), see Brink 1994, 229-30. For reasons against rejecting (A), see Pietroski 1993, 503-4, and Zimmerman 1996, 213-4. See also Streumer 2005.
} 
According to some philosophers, if determinism is true, this undermines many claims about what we ought to do. One argument that these philosophers give for this conclusion is this. ${ }^{10}$ Suppose that the following version of $(\mathrm{O})$ is true:

(O') It cannot be the case that a person ought to perform an action if there is no nomologically and historically accessible possible world in which this person will perform this action.

(D) and (O') together entail:

(6) It cannot be the case that a person ought to perform an action if this person will not in fact perform this action.

And if (6) is true, the following claim must also be true:

(7) It cannot be the case that a person ought to have performed an action if this person did not in fact perform this action. ${ }^{11}$

Therefore, according to the philosophers who give this argument, if determinism is true, it cannot be the case that we ought to do anything other than what we will in fact do, and it cannot be the case that we ought to have done anything other than what we have in fact done. But other philosophers disagree, and reject either $(\mathrm{O})$ or the version of $(\mathrm{O})$ that this argument appeals to. $^{12}$

It matters whether there are moral dilemmas of the form exemplified by (1), (2) and (3), and it matters whether determinism is compatible with claims about what we ought to do.

\footnotetext{
${ }^{10}$ See Broad 1952, Haji 1998, 53-4, and Haji 2002, 59-77. For discussion of Haji's argument, see Pereboom 2001, 141-8, and Fischer 2003.

${ }^{11}$ I assume here that 'ought to have performed' is simply the past tense of 'ought to perform'

${ }^{12}$ See, for example, Fischer 2003, 248.
} 
Therefore, it matters whether $(\mathrm{O})$ is true.

\section{The interpretation of $(\mathrm{O})$}

If $(\mathrm{O})$ is true, the claim that

(8) Person P ought to perform action $\mathrm{X}$

entails the claim that

(9) Person $\mathrm{P}$ can perform action $\mathrm{X}$.

Because (8) and (9) can each be interpreted in different ways, (O) can also be interpreted in different ways.

(8) can be interpreted as having the same truth-conditions as one of at least the following four claims:

(8 $\mathrm{a}$ ) Person $\mathrm{P}$ has an obligation to perform action $\mathrm{X}$.

$\left(8_{b}\right) \quad$ One would expect person $\mathrm{P}$ to perform action $\mathrm{X}$.

(8c) It would be good if person $\mathrm{P}$ performed action $\mathrm{X}$.

$\left(8_{\mathrm{d}}\right)$ There is most reason for person $\mathrm{P}$ to perform action $\mathrm{X} .{ }^{13}$

$\left(8_{\mathrm{d}}\right)$ uses the term 'reason' to mean pro tanto normative reason. ${ }^{14}$ If the term 'reason' is used

\footnotetext{
${ }^{13}$ For some or all of these interpretations of (8), see Frankena 1950, Broad 1952, 205, Stocker 1971, 304-5, Humberstone 1971, White 1975, 139-42, Williams 1981, 114-23, Zimmerman 1996, 15, Parfit 1997, 121, Copp 1997, 446, Harman 2000, 6, Haji 2002, 14-15, and Fischer 2003, 249.

${ }^{14}$ For this use of the term 'reason', see Raz 1990, Parfit 1997, Scanlon 1998, Audi 2004 and Dancy 2004b. For a critical discussion of this use of the term 'reason', see Broome 2004.
} 
in this way, each reason has a certain weight, and there is most reason for a person to perform an action if and only if the reasons for this person to perform this action outweigh the reasons for this person not to perform this action. And if the term 'reason' is used in this way, instead of saying that there is most reason for a person to perform an action, we can also say that this person ought to perform this action. ${ }^{15}$

That (8) can be interpreted in these four ways can be illustrated with examples like the following:

It would be wrong to break your promise, so you ought to keep it. (That is, you have an obligation to keep it.)

The train journey takes about an hour and Fred's train left an hour ago, so Fred ought to arrive any time now. (That is, one would expect Fred to arrive any time now.) Everyone ought to be happy. (That is, it would be good if everyone were happy.) I have thought about the reasons for taking the job and the reasons against taking it, and I conclude that I ought to take it. (That is, I conclude that there is most reason for me to take it.)

However, if (8) is interpreted as having the same truth-conditions as $\left(8_{b}\right)$ or $\left(8_{c}\right),(O)$ is clearly false. For it can clearly be true that it would be good if a person performed an action even

\footnotetext{
${ }^{15}$ See, for example, Parfit 1997, 121. It may be objected that this ignores so-called 'enticing' reasons, which are reasons that are given by the fact that performing action $\mathrm{X}$ would be nice, fun, amusing, and so on, and which cannot make it the case that a person ought to perform an action (see Raz 1999, 101-2, Dancy 2004a, and Dancy 2004b, 21-5). However, if enticing reasons cannot make it the case that a person ought to perform an action, I could instead interpret (8) as having the same truth-conditions as the following claim: $\left(8_{\mathrm{e}}\right)$ There is most non-enticing reason for person $\mathrm{P}$ to perform action $\mathrm{X}$ (taking 'non-enticing' reasons to be all reasons that are not enticing reasons). I could then interpret $(O)$ as saying that $\left(8_{e}\right)$ entails a version of $(9)$. Since $(R)$ is a claim about all reasons, $(\mathrm{R})$ entails this interpretation of $(\mathrm{O})$, and my arguments for the truth of $(\mathrm{R})$ are also arguments for the truth of this interpretation of $(\mathrm{O})$.
} 
though this person cannot perform this action, ${ }^{16}$ and it can clearly be true that one would expect a person to perform an action even though, unknown to us, this person cannot perform this action. ${ }^{17}$ Some philosophers conclude from this that $(\mathrm{O})$ is false. ${ }^{18}$ But since it is clear that philosophers who endorse $(\mathrm{O})$ do not mean to say that $\left(8_{\mathrm{b}}\right)$ or $\left(8_{\mathrm{c}}\right)$ entail $(9)$, I think we should not interpret $(\mathrm{O})$ as saying that $\left(8_{\mathrm{b}}\right)$ or $\left(8_{\mathrm{c}}\right)$ entail $(9){ }^{19}$

(9) can be interpreted as having the same truth-conditions as one of at least the following three claims:

(9a) It is possible that person $\mathrm{P}$ will perform action $\mathrm{X}$.

$\left(9_{b}\right) \quad$ It is possible that person $\mathrm{P}$ will perform action $\mathrm{X}$ and it is possible that person $\mathrm{P}$ will not perform action $\mathrm{X}$.

$\left(9_{c}\right) \quad$ It is possible that person $\mathrm{P}$ will perform action $\mathrm{X}$, it is possible that person $\mathrm{P}$ will not perform action $\mathrm{X}$, and person $\mathrm{P}$ controls whether or not he or she will perform action $\mathrm{X}$.

It is difficult to give examples to illustrate that (9) can be interpreted in these three ways, but $\left(9_{b}\right)$ is what philosophers normally mean when they say that a person has alternative possibilities with regard to an action, and $\left(9_{c}\right)$ is what they normally mean when they say that it is up to a person whether or not he or she performs an action. ${ }^{20}$

\footnotetext{
${ }^{16}$ For example, it can be true that it would be good if everyone were happy, even though not everyone can be happy. For a different example, see Humberstone 1971.

${ }^{17}$ For example, it can be true that one would expect Fred to arrive any time now, even though, unknown to us, he cannot arrive any time now, because he has been in a train crash. For a different example, see White 1975, 148. Frankena 1950, 157, thinks that the claim that the train ought to arrive any time now does entail that the train can arrive any time now, but perhaps Frankena takes this 'can' to be an epistemic or a doxastic 'can', which would make it mean 'can, for all we know' or 'can, for all we believe'.

${ }^{18}$ See, for example, White 1975, 148.

${ }^{19}$ A similar conclusion is drawn by Sidgwick 1907, 33, Moore 1922, 317-9, and Zimmerman 1996.

${ }^{20}$ For such a claim about alternative possibilities, see Frankfurt 1969. For such a claim about it
} 
However, if (9) is interpreted as having the same truth-conditions as $\left(9_{\mathrm{b}}\right)$ or $\left(9_{\mathrm{c}}\right),(\mathrm{O})$ may again be false. Harry Frankfurt has given a famous example in which a person chooses to perform an action even though, if this person had not chosen to perform this action, someone else would have forced this person to perform this action anyway. ${ }^{21}$ Though Frankfurt gave this example to refute a principle about moral responsibility, the example may also show that (8) does not entail $\left(9_{b}\right)$ or $\left(9_{c}\right)$. I am not sure whether it does, but I think that, if it does, we should not interpret $(\mathrm{O})$ as saying that $(8)$ entails $\left(9_{\mathrm{b}}\right)$ or $\left(9_{\mathrm{c}}\right){ }^{22}$

According to some philosophers, (9) can also be interpreted as having the same truthconditions as the following claim:

$\left(9_{d}\right) \quad$ If person $P$ chose to perform action $X$, person $P$ would perform action $X .^{23}$

However, suppose that Jack has taken a drug that makes it impossible for him to choose to get up from his chair. In that case, it is true that Jack would get up if he chose to get up, since the closest possible worlds in which Jack chooses to get up are worlds in which he has not

being up to a person whether or not he or she performs an action, see Lehrer 1960, 146-50, and Taylor 1962, 59-61.

${ }^{21}$ See Frankfurt 1969. For further discussion, see van Inwagen 1978 and 1983, Kane 1985 and 1996, Lamb 1993, Fischer 1994, Widerker 1991, 1995 and 2000, Copp 1997, Mele and Robb 1998, Yaffe 1999, Ekstrom 2000, Blum 2000, Schnall 2001, and Haji 1998 and 2002.

${ }^{22}$ Frankfurt would probably agree, since he claims that his examples do not show that (8) does not entail (9 $9_{\mathrm{a}}$ ) (see Frankfurt 1983, 95-6). But according to Widerker 1991, Copp 1997, Blum 2000 and Schnall 2001, given certain assumptions, the claim that (8) entails a version of $\left(9_{\mathrm{a}}\right)$ entails the principle of alternate possibilities, which is the principle that Frankfurt's example is meant to refute. I am not sure whether these assumptions are correct (see Zimmerman 1996, 85-9, and Yaffe 1999 for reasons to doubt that they are correct), and I am not sure whether their version of $\left(9_{\mathrm{a}}\right)$ is the same as (9a) as I have formulated it (see Schnall 2001, 338 n. 5). But if both of these things are the case, I think the arguments I give below not only show that we should accept (O), but also show that we should accept the principle of alternate possibilities. As Copp 1997, 446, suggests, we should then reject our initial intuitions about Frankfurt's example.

${ }^{23}$ See Moore 1912, 11-2, 103-5, 110, Baier 1963, Ewing 1964, and Aune 1967. 
taken this drug. But, in this example, it does not seem to be true that Jack can get up. Therefore, I think we should not interpret (9) as having the same truth-conditions as $\left(9_{d}\right){ }^{24}$ $\left(9_{\mathrm{a}}\right)$ can itself be interpreted as having the same truth-conditions as one of the following three claims:

$\left(9_{\mathrm{a}-\mathrm{a}}\right)$ There is a possible world in which person $\mathrm{P}$ will perform action $\mathrm{X}$.

$\left(9_{\mathrm{a}-\mathrm{b}}\right)$ There is a nomologically and historically accessible possible world in which person $\mathrm{P}$ will perform action $\mathrm{X}$.

$\left(9_{\text {a-c }}\right)$ There is a nomologically and historically accessible or close possible world in which person $\mathrm{P}$ will perform action $\mathrm{X}^{25}$

However, if $\left(9_{\mathrm{a}}\right)$ is interpreted as having the same truth-conditions as $\left(9_{\mathrm{a}-\mathrm{a}}\right),(\mathrm{O})$ is almost trivially true. For it is true of almost any person and almost any action that there is a possible world in which this person performs this action. Therefore, I think we should not interpret (O) as saying only that $(8)$ entails $\left(9_{\mathrm{a}-\mathrm{a}}\right)$. But since I am not sure whether we should interpret $\left(9_{\mathrm{a}}\right)$ as having the same truth-conditions as $\left(9_{\mathrm{a}-\mathrm{b}}\right)$ or as $\left(9_{\mathrm{a}-\mathrm{c}}\right)$, I shall remain neutral about how we should interpret $\left(9_{\mathrm{a}}\right)$ instead.

I conclude that there are two plausible interpretations of $(\mathrm{O})$. If $(\mathrm{O})$ is interpreted in the first way, it says that the claim that

(8) Person $\mathrm{P}$ has an obligation to perform action $\mathrm{X}$

entails the claim that

\footnotetext{
${ }^{24}$ See Chisholm 1966, 15-6. For a more general argument for the same conclusion, see Lehrer 1966, 195-7, and Lehrer 1968. Though this means that we should not interpret (O) as saying that (8) entails $\left(9_{d}\right)$, the claim that $(8)$ entails $\left(9_{d}\right)$ may nevertheless be a plausible competitor to $(O)$. I shall come back to this in section 3 .

${ }^{25}$ A possible world is nomologically and historically close if and only if its laws of nature and its past are similar to the laws of nature and the past of the actual world.
} 
(9a) It is possible that person $\mathrm{P}$ will perform action $\mathrm{X}$.

If $(\mathrm{O})$ is interpreted in the second way, it says that the claim that

(8d) There is most reason for person $\mathrm{P}$ to perform action $\mathrm{X}$

entails the claim that

(9) It is possible that person $\mathrm{P}$ will perform action $\mathrm{X}$.

In what follows, I shall interpret (O) in the second of these two ways. If $(\mathrm{O})$ is interpreted in this way, it has the same truth-conditions as the following claim:

(M) It cannot be the case that there is most reason for a person to perform an action if it is impossible that this person will perform this action.

On $\left(8_{d}\right)$ and $(M)$ 's use of the term 'reason', there is most reason for a person to perform an action if and only if the reasons for this person to perform this action outweigh the reasons for this person not to perform this action. Therefore, on this use of the term 'reason', if there cannot be a reason for a person to perform an action that it is impossible for this person to perform, there also cannot be most reason for a person to perform an action that it is impossible for this person to perform. (M) is therefore entailed by the following claim:

(R) There cannot be a reason for a person to perform an action if it is impossible that this person will perform this action.

And since $(\mathrm{M})$ has the same truth-conditions as $(\mathrm{O})$ as I interpret it, $(\mathrm{R})$ also entails $(\mathrm{O})$ as I interpret it.

Though (R) entails (O) as I interpret it, $(\mathrm{O})$ as I interpret it does not entail (R). In this sense, if $(R)$ is true, its truth is more fundamental than the truth of $(O)$ as I interpret it. 
Moreover, some philosophers endorse (O), but reject (R). ${ }^{26}$ Therefore, instead of arguing directly for the truth of $(\mathrm{O})$, I shall now give three arguments for the truth of (R). ${ }^{27}$ After I have given these arguments, I shall ask whether they show that $(\mathrm{O})$ is true in a sense that can support the arguments about moral dilemmas and determinism that I discussed in section 1.

\section{The argument from crazy reasons}

My first argument for the truth of $(\mathrm{R})$ is:

The argument from crazy reasons. Suppose that $(\mathrm{R})$ is false. In that case, unless there are other restrictions on the reasons there can be for a person, the following claims seem to be true:

(10) Suppose that Jane is a person living in the twenty-first century. Given how bad the crusades, slavery and the two world wars were, there are reasons for Jane to prevent the crusades, slavery and the two world wars, even though, to do this, she would have to travel back in time and single-handedly change the course of history. ${ }^{28}$

\footnotetext{
${ }^{26}$ See, for example, Fischer 2003.

${ }^{27}$ However, these arguments can all be reformulated as direct arguments for the truth of (O), by replacing their claims about actions that there is a reason for a person to perform with claims about actions that this person ought to perform.

28 'Given how bad the crusades, slavery and the two world wars were', because this is what makes it likely that, on any plausible moral view, there would be this reason for Jane if (R) were false. It may be objected that my use of the phrase 'given how bad the crusades, slavery and the two world wars were' shows that the argument from crazy reasons presupposes a form of consequentialism. However, on any plausible moral view, extreme badness will normally be connected to strong reasons. Therefore, in so far as this argument presupposes a form of consequentialism, this form of consequentialism is presupposed by any plausible moral view.
} 
(11) Suppose that Bob is standing on the ground and that, above him, there is a plane full of passengers that has failing engines. Given how bad it is if a plane full of passengers crashes, there is a reason for Bob to save the passengers on this plane, even though, to do this, he would have to jump 30,000 feet into the sky and single-handedly repair this plane's engines.

(12) Suppose that Susan is a moderately intelligent person. Given how important it is to save the lives of people who have deadly diseases, there is a reason for Susan to develop new medicines to save the lives of everyone who has a deadly disease, even though, if she tried to do this, she would be trying to develop these medicines until she dies, without ever succeeding.

It seems that there cannot be such crazy reasons. Therefore, either $(\mathrm{R})$ is true, or there are other restrictions on the reasons there can be for a person.

Philosophers who do not want to accept (R) could reply to this argument that there can be such crazy reasons, but that these reasons are always outweighed by other reasons. However, if crazy reasons were always outweighed by other reasons, I could reformulate $(R)$ as:

(R') There cannot be a reason for a person to perform an action that is not outweighed by other reasons if it is impossible that this person will perform this action.

And like (R), (R') entails (O) as I interpret it. ${ }^{29}$

\footnotetext{
${ }^{29}$ Moreover, given the amount of good that would be brought about if Jane, Bob and Susan performed these actions, it is very unlikely that if there were reasons for them to perform these actions, these reasons would always be outweighed by other reasons. Philosophers who do not want to accept $(\mathrm{R})$ could also claim that there can be such crazy reasons because Jane, Bob and Susan can believe that there are reasons for them to perform these actions, or because Jane, Bob and Susan can be motivated to perform these actions. However, these philosophers' use of the term 'reason' would
} 
Philosophers who do not want to accept (R) could also reply to the argument from crazy reasons that, instead of showing that $(\mathrm{R})$ is true, the argument merely shows that there are other restrictions on the reasons there can be for a person, such as:

There cannot be a reason for a person to perform an action if, in order to perform this action, this person would have to travel back in time.

There cannot be a reason for a person to perform an action if, in order to perform this action, this person would have to do something that he or she is physically incapable of.

There cannot be a reason for a person to perform an action if, in order to perform this action, this person would have to acquire beliefs that it is beyond his or her intellectual powers to acquire.

However, if these philosophers endorsed such other restrictions on the reasons there can be for a person, they would face two problems. The first problem is that I could keep adding further clauses to the argument from crazy reasons, and to avoid admitting that the argument shows that $(\mathrm{R})$ is true, these philosophers would then have to keep endorsing further restrictions on the reasons there can be for a person. The second problem is that, for each restriction that these philosophers endorse, I can ask:

Why is it the case that there cannot be a reason for a person to perform an action if, in order to perform this action, this person would have to travel back in time?

Why is it the case that there cannot be a reason for a person to perform an action if, in

then be different from mine. If they claimed that there can be such crazy reasons because Jane, Bob and Susan can believe that there are reasons for them to perform these actions, they would probably be using the term 'reason' to mean prima facie (or apparent) normative reason rather than pro tanto normative reason. And if these philosophers claimed that there can be such crazy reasons because Jane, Bob and Susan can be motivated to perform these actions, they would probably be using the term 'reason' to mean motivating reason rather than pro tanto normative reason. 
order to perform this action, this person would have to do something that he or she is physically incapable of?

Why is it the case that there cannot be a reason for a person to perform an action if, in order to perform this action, this person would have to acquire beliefs that it is beyond his or her intellectual powers to acquire?

And the problem for these philosophers is that the obvious answers to these questions seem to be:

Because it is impossible that a person will travel back in time.

Because it is impossible that a person will do something that he or she is physically incapable of.

Because it is impossible that a person will acquire beliefs that it is beyond his or her intellectual powers to acquire.

In other words, the problem for these philosophers is that, unless they endorse $(\mathrm{R})$, they cannot explain why what unifies all these restrictions on the reasons there can be for a person seems to be the truth of $(\mathrm{R})$.

Finally, philosophers who do not want to accept (R) could reply to the argument from crazy reasons that, instead of showing that $(\mathrm{R})$ is true, the argument merely shows that the claim that

(13) There is a reason for person $\mathrm{P}$ to perform action $\mathrm{X}$

entails the claim that

$\left(9_{d}\right)$ If person $\mathrm{P}$ chose to perform action $\mathrm{X}$, person $\mathrm{P}$ would perform action $\mathrm{X}$, from which it does not follow that (13) also entails the claim that

(9 ${ }_{\mathrm{a}}$ It is possible that person $\mathrm{P}$ will perform action $\mathrm{X}$. 
However, to deal with this reply, I could add the following clause to the argument from crazy reasons:

(14) Suppose that Jack has just been knocked unconscious by a car and is lying on the pavement beside a busy road, and suppose that there is an old lady trying to cross this road. Given how important it is that old ladies are not hit by cars when they cross busy roads, there is a reason for Jack to help this old lady cross the road. ${ }^{30}$

If Jack chose to help this old lady cross the road, he would help her cross the road, since in the closest possible worlds in which Jack chooses to help this old lady cross the road he has not been knocked unconscious by a car. ${ }^{31}$ Therefore, it seems that philosophers who claim that (13) only entails $\left(9_{\mathrm{d}}\right)$ have to claim that there is a reason for Jack to help this old lady cross the road. But given that Jack has been knocked unconscious by a car, it is hard to believe that there is such a reason. And therefore, it is hard to believe that (13) merely entails $\left(9_{d}\right)$, and does not entail $\left(9_{\mathrm{a}}\right)$.

I conclude that, rather than merely showing that there are other restrictions on the reasons there can be for a person or that (13) merely entails $\left(9_{d}\right)$, the argument from crazy reasons shows that $(\mathrm{R})$ is true.

\footnotetext{
${ }^{30}$ For a similar example, and further discussion, see van Inwagen 1983, 119-21.

${ }^{31}$ It may be objected that, in the closest possible worlds in which Jack chooses to help this old lady cross the road, Jack has not been knocked unconscious by a car but he has nevertheless been hit by this car. However, suppose that Jack has been knocked unconscious by this car because the driver failed to concentrate for just one moment. In that case, the closest possible world in which Jack chooses to help this old lady cross the road is a world in which this driver did not fail to concentrate (or did not fail to concentrate at the same moment), and in which Jack is therefore not hit by a car at all.
} 


\section{The argument from tables and chairs}

I shall now give my second argument for the truth of $(\mathrm{R})$. This argument is:

The argument from tables and chairs. There cannot be a reason for a table or a chair to perform an action, because it is impossible for a table or a chair to perform an action. When it is impossible for a person to perform an action, this person is in the same position with regard to this action that a table or a chair is in with regard to all actions. Therefore, just as there cannot be a reason for a table or a chair to perform an action, there cannot be a reason for this person to perform this action. And therefore, $(\mathrm{R})$ is true.

In reply to this argument, philosophers who do not want to accept $(\mathrm{R})$ could claim that what explains why there cannot be a reason for a table or a chair to perform an action is not that

(15) It cannot be the case that there is a reason for a thing to perform an action if this thing cannot perform this action,

but is instead that

(16) It cannot be the case that there is a reason for a thing to perform an action if this thing does not have the capacity to be rational. ${ }^{32}$

For whereas a table or a chair does not have the capacity to be rational, these philosophers could claim, a person does have this capacity, even if this person cannot perform a particular action. And if what explains why there cannot be a reason for a table or a chair is (15) rather than (16), they could claim, the argument from tables and chairs fails to show that $(R)$ is true.

\footnotetext{
${ }^{32}$ I here use the term 'thing' to cover both persons and inanimate objects like tables and chairs.
} 
For though substituting 'person' for 'thing' in (15) gives us (R), substituting 'person' for 'thing' in (16) does not.

By the capacity to be rational, these philosophers could mean one of the following two things:

(i) The capacity to comply with reasons, that is, the capacity to perform actions that there is a reason to perform.

(ii) The capacity to respond to reasons, that is, the capacity to perform actions that there is a reason to perform on the basis of the belief that there is a reason to perform these actions. ${ }^{33}$

Suppose that what these philosophers mean by the capacity to be rational is the capacity to comply with reasons. In that case, what their reply to the argument from tables and chairs comes down to is that what explains why there cannot be a reason for a table or a chair to perform an action is not that

(15) It cannot be the case that there is a reason for a thing to perform an action if this thing cannot perform this action,

but is instead that

(16a) It cannot be the case that there is a reason for a thing to perform an action if this thing cannot perform any actions at all.

However, suppose that Kate cannot perform any actions at all. In that case, if either (15) or $\left(16_{a}\right)$ is true, there cannot be reasons for her to perform any action. But now suppose that

\footnotetext{
${ }^{33}$ For this contrast between complying with reasons and responding to reasons, see Raz 1990, 17882.
} 
there is a small change in Kate's situation, such that there is now exactly one action that she can perform. If $\left(16_{a}\right)$ is true but (15) is false, and if there are no other restrictions on the reasons there can be for a person, there can then all of a sudden be reasons for Kate to perform any action whatsoever. It is hard to believe that, because of this very small change in Kate's situation, there is this enormous change in the number of reasons there can be for Kate. Therefore, it is hard to believe that $\left(16_{a}\right)$ is true, but that (15) is false. ${ }^{34}$

Alternatively, suppose that what these philosophers mean by the capacity to be rational is the capacity to respond to reasons. In that case, what their reply to the argument from tables and chairs comes down to is that what explains why there cannot be a reason for a table or a chair to perform an action is not that

(15) It cannot be the case that there is a reason for a thing to perform an action if this thing cannot perform this action,

but is instead that

$\left(16_{b}\right)$ It cannot be the case that there is a reason for a thing to perform an action if this thing cannot have beliefs about which actions there is a reason for it to perform.

However, suppose that Fred is completely and irreversibly paralyzed, but suppose that he is able to have beliefs about which actions there is a reason for him to perform. In that case, if $\left(16_{b}\right)$ is true but (15) is false, and if there are no other restrictions on the reasons there can be for a person, there can be reasons for Fred to perform a wide variety of actions. For example, if Fred is hungry, there can be a reason for him to cook dinner for himself, even though he cannot cook dinner for himself. If Susan asks Fred to pick her up from the train station, there

\footnotetext{
${ }^{34}$ That is not to say that it is hard to believe that $\left(16_{a}\right)$ is true: on the contrary, if (15) is true, so is $\left(16_{\mathrm{a}}\right)$. Rather, what is hard to believe is that $\left(16_{\mathrm{a}}\right)$ is true and that $(15)$ is false.
} 
can be a reason for him to pick her up from the train station, even though he cannot pick her up from the train station. If Fred hears someone screaming for help outside his house, there is a reason for him to go outside and help this person, even though he cannot help this person. Given that Fred is completely and irreversibly paralyzed, it is hard to believe that there can be reasons for him to perform these actions. Therefore, it is hard to believe that $\left(16_{b}\right)$ is true, but that (15) is false. ${ }^{35}$

I conclude that, rather than showing that $\left(16_{a}\right)$ or $\left(16_{b}\right)$ is true, the argument from crazy reasons shows that (15) is true. And since substituting 'person' for 'thing' in (15) gives us $(\mathrm{R})$, I conclude that the argument shows that $(\mathrm{R})$ is true.

\section{The argument from deliberation}

Finally, I shall give my third argument for the truth of $(\mathrm{R})$. This argument is:

The argument from deliberation. Suppose that $(\mathrm{R})$ is false, and that there are no other restrictions on the reasons there can be for a person. In that case, whenever a person engages in rational deliberation about what to do, this person will not only have to judge which reasons there are to perform actions that he or she can perform, but will also have to judge which reasons there are to perform actions that he or she cannot perform. Given the enormous amount of suffering that was caused by the crusades, slavery and the two world wars, this person will then almost always have to conclude that there is most reason for him or her to travel back in time and prevent the crusades, slavery and the two world wars. And this person will then have to try to travel back in time to prevent the crusades, slavery and the two world wars, even though it is pointless for this person to try to do this. Therefore, if $(\mathrm{R})$ is false, rational

\footnotetext{
${ }^{35}$ That is not to say that it is hard to believe that $\left(16_{\mathrm{b}}\right)$ is true: on the contrary, $\left(16_{\mathrm{b}}\right)$ may well be true. Rather, what is hard to believe is that $\left(16_{b}\right)$ is true and that (15) is false.
} 
deliberation will almost always result in a person pointlessly trying to perform actions that he or she cannot perform. Surely, rational deliberation should not have such pointless results. Therefore, either $(\mathrm{R})$ is true, or there is something else that prevents rational deliberation from having such results. ${ }^{36}$

In reply to this argument, philosophers who do not want to accept $(\mathrm{R})$ could claim that there are two kinds of reason:

(i) Reasons for a person to perform an action which it is possible for this person to perform.

(ii) Reasons for a person to perform an action which it is impossible for this person to perform.

They could then make one of the following claims:

(17) When a person judges which reasons there are for or against his or her performing an action, this person should only take into account reasons of kind (i).

(18) When a person judges which action there is most reason for him or her to perform, this person should only take into account reasons of kind (i).

(19) When a person tries to perform the action that there is most reason for him or her to perform, this person should only take into account reasons of kind (i).

\footnotetext{
${ }^{36}$ It may be objected that this argument presupposes a consequentialist view of rational deliberation. However, the argument only presupposes that the amount of suffering that an action would prevent is one factor that deliberation should take into account, and that deliberation should generally be more likely to lead us to perform an action that would prevent a large amount of suffering the larger this amount of suffering is. That is surely true on any plausible view of rational deliberation.
} 
And they could then claim that what prevents rational deliberation from resulting in a person pointlessly trying to perform actions that he or she cannot perform is not the truth of (R), but is instead the truth of (17), (18) or (19).

However, if (17), (18) or (19) are true, the only reasons that can make a difference to the result of rational deliberation are reasons of kind (i). And if that is so, why should we believe that, in addition to reasons of kind (i), there are also reasons of kind (ii)? In other words, if the only reasons that can ever make a difference to the result of rational deliberation are reasons to perform actions that it is possible to perform, why should we believe that there are also reasons to perform actions that it is impossible to perform? ${ }^{37}$

Philosophers who do not want to accept (R) could claim that reasons that are outweighed by other reasons also do not make a difference to the result of rational deliberation, and that this does not show that there are no reasons that are outweighed by other reasons. Likewise, they could claim, the fact that reasons of kind (ii) cannot make a difference to the result of rational deliberation does not show that there are no reasons of kind (ii).

However, reasons that are outweighed by other reasons do make a difference to the result of rational deliberation. For if the weight of these reasons had been greater, or if the weight of other reasons had been less, rational deliberation would have had a different result. By contrast, if (17), (18) or (19) is true, the result of rational deliberation is the same no matter how great the weight of reasons of kind (ii) is. ${ }^{38}$ Therefore, the existence of reasons

\footnotetext{
${ }^{37}$ Philosophers who do not want to accept (R) could also claim that reasons of kind (ii) are always outweighed by reasons for this person not to perform this action, or that reasons of kind (ii) are always outweighed by reasons for this person not to try to perform this action. In both of these cases, reasons of kind (ii) cannot make a difference to the result of rational deliberation. Moreover, as I have shown in section 3 above, if these philosophers made one of these claims, I could modify (R) to (R'), which entails $(\mathrm{O})$ as I interpret it.

${ }^{38}$ It may seem that a person's rational deliberation sometimes should take into account reasons to perform an action which are such that it is impossible that this person will perform this action namely, reasons that there were in the past and that this person can no longer act on, but that make it the case that there are further reasons for this person in the present. For example, if Jack broke his
} 
that are outweighed by other reasons does not show that there are also reasons of kind (ii).

Philosophers who do not want to accept $(\mathrm{R})$ could also claim that there are reasons of the following kind:

(iii) Reasons for a person to try to perform an action which it is impossible for this person to perform.

What makes it the case that there are reasons of kind (iii), these philosophers could claim, must be that there are also reasons of kind (ii). For example, suppose that there is a reason for Jack to try to run a marathon in less than two hours even though it is impossible that he will run a marathon in less than two hours. What makes it the case that there is such a reason for Jack, they could claim, must be that there is a reason for him to actually run a marathon in less than two hours.

However, what makes it the case that there is such a reason for Jack does not have to be that there is a reason for him to actually run a marathon in less than two hours. It could instead be that there is a reason for him to run a marathon as fast as he can, and that attempting to run a marathon in less than two hours is the best way for him to run a marathon as fast as he can. Or it could be that that he does not know whether he is able to run a marathon in less than two hours, and that attempting to run a marathon in less than two hours is the best way for him to find out whether he is able to do this. Therefore, the existence of reasons of kind (iii) does not show that there must also be reasons of kind (ii).

If reasons of kind (ii) cannot make a difference to the result of rational deliberation, I think we should conclude that there are no reasons of kind (ii). And if there are no reasons of kind (ii), rather than showing that (17), (18) or (19) is true, the argument from deliberation

promise to meet Susan yesterday, the fact that there was a reason for Jack to meet Susan yesterday can make it the case that there is a reason for Jack to apologize to Susan today. However, in that case, what Jack's rational deliberation should take into account (in the sense of 'taking into account' that is relevant here) is not the reason that there was for him to meet Susan yesterday, but is instead the reason that there is for him to apologize to Susan today. 
shows that $(\mathrm{R})$ is true.

\section{Objections to (R)}

I have given three arguments for the truth of (R), and I have argued that several replies to these arguments fail. It may be thought, however, that there are objections to $(\mathrm{R})$ that are independent of the arguments I have given. I shall now discuss two of these objections. ${ }^{39}$

One objection to $(\mathrm{R})$ may be thought to be:

The objection from making it impossible for oneself to do something. Suppose that there is a reason for Alice to meet Bob today, but that Alice makes it impossible for herself to meet Bob today. If $(\mathrm{R})$ is true, there can then no longer be a reason for Alice to meet Bob today. Therefore, if $(\mathrm{R})$ is true, a person can get rid of any reason there is for him or her to perform an action by making it impossible for him- or herself to perform this action. ${ }^{40}$

It is true that, if $(\mathrm{R})$ is true, once Alice has made it impossible for herself to meet Bob today, there can no longer be a reason for her to meet Bob today. But that may seem more implausible than it really is. For we may forget that, after Alice has made it impossible for herself to meet Bob today, the following claims can still be true:

\footnotetext{
${ }^{39}$ The two objections to (R) that I shall discuss can also be formulated as objections to (O), by replacing their claims about actions that there is a reason for a person to perform with claims about actions that this person ought to perform. However, my replies to these objections to (R) can be reformulated as replies to these objections to $(\mathrm{O})$ as well.

${ }^{40}$ Sinnott-Armstrong 1984 makes a version of this objection to (O). Stocker 1971, 314-5, makes a version of this objection to the claim that 'blameworthy' and 'wrong' imply 'can'. For an excellent discussion of this objection, see Zimmerman 1996, 95-113.
} 
There was a reason for Alice to meet Bob today.

There was a reason for Alice not to make it impossible for herself to meet Bob today. Because there was a reason for Alice to meet Bob today, Bob can blame Alice for not having met him today.

Because there was a reason for Alice not to make it impossible for herself to meet Bob today, Bob can blame Alice for having made it impossible for herself to meet him today.

Because Alice did not meet Bob today, there is a reason for Alice to meet him on another day instead.

Given that all of these other claim can still be true, I think it is not implausible to say, as (R) implies, that once Alice has made it impossible for herself to meet Bob today, there can no longer be a reason for her to meet Bob today. ${ }^{41}$

Another objection to $(\mathrm{R})$ may be thought to be:

The objection from evil. Suppose that Harry frequently murders innocent people, and suppose that it is impossible for him to stop murdering these people. In that case, if $(\mathrm{R})$ is true, there cannot be reasons for Harry to stop murdering these people.

Therefore, if $(\mathrm{R})$ is true, there cannot be reasons for a person to stop performing evil actions if it is impossible for this person to stop performing these actions.

It is true that, if $(\mathrm{R})$ is true, there cannot be reasons for Harry to stop murdering innocent people. But, again, that may seem more implausible than it really is. For we may take the claim that it is impossible that Harry will stop murdering these people to mean, not that this is impossible in (R)'s sense, but that this is impossible in some other sense. For example, we may take this claim to mean that

\footnotetext{
${ }^{41}$ I argue for this at greater length in Streumer 2003.
} 
Harry's character makes it extremely difficult for him to stop murdering innocent people.

This is what philosophers usually mean when they say that a person is psychologically incapable of doing something. ${ }^{42}$ However, if it is merely impossible in this sense for Harry to stop murdering innocent people, $(\mathrm{R})$ does not say that there cannot be reasons for him to stop murdering these people. (R) only says that there cannot be reasons for Harry to stop murdering innocent people if there is no nomologically and historically accessible or close possible world in which he stops murdering these people.

Another reason why what $(\mathrm{R})$ says may seem more implausible than it really is is that we may forget that, if there cannot be reasons for Harry to stop murdering innocent people, the following claims can still be true:

Harry is evil.

It is extremely bad that Harry murders innocent people.

Because it is extremely bad that Harry murders innocent people, there are reasons for us to prevent him from murdering these people.

There are reasons for us to punish Harry for having murdered these innocent people. ${ }^{43}$

Given that all of these claims can still be true, I think it is not implausible to say, as (R) does, that if it is impossible in (R)'s sense for Harry to stop murdering innocent people, there cannot be reasons for him to stop murdering these people.

I have given three arguments for the truth of (R), I have argued that several replies to these arguments fail, and I have shown that two other objections to (R) are not as plausible as they may seem. I think we should conclude from this that $(R)$ is true. And since $(R)$ entails

\footnotetext{
${ }^{42}$ See, for example, Stocker 1971, 311.

${ }^{43}$ We may think that, if there are no reasons for Harry to stop murdering innocent people, there cannot be reasons for us to punish Harry for having murdered these people. However, accepting (R) does not commit us to such a view about punishment.
} 
(O) as I interpret it, I think we should conclude that $(\mathrm{O})$ as I interpret it is true as well.

\section{Is $(O)$ true in a sense that matters?}

Even if $(\mathrm{O})$ as I interpret it is true, it may still be asked whether $(\mathrm{O})$ as I interpret it can support the arguments about moral dilemmas and determinism that I discussed in section 1.

Consider first the argument about moral dilemmas. According to philosophers who give this argument, there cannot be moral dilemmas of the following form:

(1) Person P ought to perform action A.

(2) Person P ought to perform action B.

(3) Person $\mathrm{P}$ cannot both perform action A and perform action B.

That is so, these philosophers say, because if we combine $(\mathrm{O})$ with a principle of agglomeration that says that

(A) If a person ought to perform action $\mathrm{X}$ and this person ought to perform action $\mathrm{Y}$, then this person ought to both perform action $\mathrm{X}$ and perform action $\mathrm{Y}$,

then (1) and (2) entail that

(5) Person $\mathrm{P}$ can both perform action $\mathrm{A}$ and perform action $\mathrm{B}$,

which contradicts (3).

The are two ways in which (O) as I interpret it could fail to support this argument. First, the argument could require that the claim that

(9) Person $\mathrm{P}$ can perform action $\mathrm{X}$

is entailed by one of the following claims: 
(8 $\mathrm{a}$ Person $\mathrm{P}$ has an obligation to perform action $\mathrm{X}$.

$\left(8_{\mathrm{b}}\right) \quad$ One would expect person $\mathrm{P}$ to perform action $\mathrm{X}$.

$\left(8_{c}\right) \quad$ It would be good if person $\mathrm{P}$ performed action $\mathrm{X}$.

Though philosophers who think that there can be moral dilemmas of this form do not interpret (1) and (2) as claims about what one would expect person P to do or as claims about what it would be good for person P to do, many of these philosophers do interpret (1) and (2) as claims about what person $\mathrm{P}$ has an obligation to do. ${ }^{44}$ However, it is plausible to suppose that there is a connection between obligations and reasons such that one of the following claims is true:

Obligations are reasons of a particular kind.

The fact that a person has an obligation to do something is a reason for this person to do this thing.

What makes it the case that a person has an obligation to do something also makes it the case that there is a reason for this person to do this thing. ${ }^{45}$

${ }^{44}$ At least, Lemmon 1962, Williams 1973, van Fraassen 1973 and Marcus 1980 do not seem to interpret (1) and (2) as claims about what one would expect person P to do or as claims about what it would be good for person P to do. Railton 1996, 146-7, does suggest that claims such as (1) and (2) can be interpreted as claims about what it would be best for person P to do. However, if (1) and (2) are interpreted in this way, the existence of moral dilemmas as exemplified by (1), (2) and (3) does not cause the trouble for deontic logic that the existence of such dilemmas is often said to cause.

${ }^{45}$ It is plausible to suppose that one of these claims is true, but not that all of these claims are true. For if obligations are reasons, it seems that the fact that a person has an obligation to do something will not normally be an (additional) reason for this person to do this thing, and it seems that what makes it the case that a person has an obligation to do something will not normally also make it the case that there is an (additional) reason for this person to do this thing. And if the fact that a person has an obligation to do something is a reason for this person to do this thing, it seems that what makes it the case that a person has this obligation to do this thing will not normally also make it the case that there is a reason for this person to do this thing (in addition to the reason given by the fact that this person has this obligation to do this thing). 
If one of these claims is true, $(\mathrm{R})$ not only entails $(\mathrm{O})$ as I interpret it, but also entails the claim that $\left(8_{\mathrm{a}}\right)$ entails $(9)$. Therefore, I think that $(\mathrm{O})$ as I interpret it does not fail to support this argument in the first way.

The second way in which $(\mathrm{O})$ as I interpret it could fail to support this argument is that the argument could require that the claim that

(8) Person P ought to perform action X

entails one of the following claims:

(9b) It is possible that person $\mathrm{P}$ will perform action $\mathrm{X}$ and it is possible that person $\mathrm{P}$ will not perform action $\mathrm{X}$.

(9c) It is possible that person $\mathrm{P}$ will perform action $\mathrm{X}$, it is possible that person $\mathrm{P}$ will not perform action $\mathrm{X}$, and person $\mathrm{P}$ controls whether or not he or she will perform action $\mathrm{X}$.

$\left(9_{\mathrm{d}}\right)$ If person $\mathrm{P}$ chose to perform action $\mathrm{X}$, person $\mathrm{P}$ would perform action X.

Philosophers who think that there can be moral dilemmas of this form normally interpret (3) as the claim that it is not possible that person $\mathrm{P}$ will perform both action $\mathrm{A}$ and perform action B. That is, they interpret (3) in a way that is analogous to the negation of $\left(9_{a}\right)$, and they do not interpret (3) in a way that is analogous to the negations of $\left(9_{b}\right)$ or $\left(9_{c}\right)$. They would probably agree that it is not the case that if person $\mathrm{P}$ chose to perform both of these actions he or she would perform both of these actions, but this claim does not conflict with their interpretation of (3) as the claim that it is not possible that person $\mathrm{P}$ will both perform action A and perform action B. ${ }^{46}$ Therefore, I think that $(\mathrm{O})$ as I interpret it also does not fail to support this argument in the second way. ${ }^{47}$

\footnotetext{
${ }^{46}$ Moreover, the arguments that I have given to show that $(\mathrm{O})$ is true also show that $(8)$ entails $\left(9_{\mathrm{d}}\right)$.

${ }^{47}$ However, if these philosophers interpreted (3) merely as the claim that there is no nomologically
} 
Consider next the argument about the compatibility of determinism with claims about what we ought to do. According to philosophers who give this argument, if it is true that

(O') It cannot be the case that a person ought to perform an action if there is no nomologically and historically accessible possible world in which this person will perform this action,

then given that determinism can be formulated as

(D) There is no nomologically and historically accessible possible world the future of which is different from the future of the actual world,

the truth of determinism entails:

(6) It cannot be the case that a person ought to perform an action if this person will not in fact perform this action.

(7) It cannot be the case that a person ought to have performed an action if this person did not in fact perform this action.

For $(\mathrm{O})$ to support this argument, it must have the same truth-conditions as $\left(\mathrm{O}^{\prime}\right)$. In other words, for $(\mathrm{O})$ to support this argument, $(\mathrm{O})$ must be interpreted as saying that the claim that

$$
\text { Person } \mathrm{P} \text { ought to perform action } \mathrm{X}
$$

and historically accessible possible world in which person $\mathrm{P}$ will both perform action A and perform action B, the truth of (3) would be compatible with the existence of a nomologically and historically close possible world in which person $\mathrm{P}$ will both perform action $\mathrm{A}$ and perform action $\mathrm{B}$. And in that case, $(\mathrm{O})$ would not fully support this argument, since I have left it open whether we should interpret $\left(9_{\mathrm{a}}\right)$ as having the same truth-conditions as $\left(9_{\mathrm{a}-\mathrm{b}}\right)$ or as having the same truth-conditions as $\left(9_{\mathrm{a}-\mathrm{c}}\right)$. 
entails the claim that

(9a-b) There is a nomologically and historically accessible possible world in which person $\mathrm{P}$ will perform action $\mathrm{X}$.

I have not interpreted $(O)$ as saying that $(8)$ entails $\left(9_{\mathrm{a}-\mathrm{b}}\right)$, because I am not sure whether it is plausible to interpret $(\mathrm{O})$ in this way. As I have said in section 2, $(\mathrm{O})$ can also be interpreted as saying that (8) entails the claim that

$(9 \mathrm{a}-\mathrm{c})$ There is a nomologically and historically accessible or close possible world in which person $\mathrm{P}$ will perform action $\mathrm{X}$.

However, nothing in my defence of $(\mathrm{O})$ rules out interpreting $(\mathrm{O})$ as saying that $(8)$ entails $\left(9_{\mathrm{a}-\mathrm{b}}\right)$. And my defence of $(\mathrm{O})$ does rule out two rival interpretations of $(\mathrm{O})$.

First, in section 2, I argued that we should not interpret (O) as saying that (8) only entails the claim that

$\left(9_{\mathrm{a}-\mathrm{a}}\right) \quad$ There is a possible world in which person $\mathrm{P}$ will perform action $\mathrm{X}$.

Moreover, the argument from crazy reasons shows that $(\mathrm{O})$ must be true in a sense that is stronger than this, since there are possible worlds in which people jump 30,000 feet into the sky, in which moderately intelligent people develop new medicines to save the lives of everyone with a deadly disease, and in which unconscious people help old ladies cross the road.

Second, in section 3, I argued that the argument from crazy reasons rules out the alternative to $(\mathrm{R})$ that says that the claim that

(13) There is a reason for person $\mathrm{P}$ to perform action $\mathrm{X}$

merely entails the claim that 
$\left(9_{\mathrm{d}}\right) \quad$ If person $\mathrm{P}$ chose to perform action $\mathrm{X}$, person $\mathrm{P}$ would perform action $\mathrm{X}$.

If the argument from crazy reasons rules out this alternative to (R), it also rules out a similar alternative to $(\mathrm{O})$. And it is this alternative to $(\mathrm{O})$ that many compatibilists have appealed to in order to show that determinism does not entail (6) and (7). ${ }^{48}$

I have not given a full defence of the truth of $(\mathrm{O})$ in a sense that can support the argument about the compatibility of determinism with claims about what we ought to do. But I have said nothing that rules out $(\mathrm{O})$ 's being true in this sense, and I have ruled out two rival interpretations of $(\mathrm{O})$. Therefore, I think that $(\mathrm{O})$ as I interpret it gives some support to this argument, even though, to defend a version of $(\mathrm{O})$ that fully supports this argument, more would need to be said.

\section{Conclusion}

I conclude that

(O) It cannot be the case that a person ought to perform an action if this person cannot perform this action,

which, as I interpret it, is equivalent to:

(M) It cannot be the case that there is most reason for a person to perform an action if it is impossible that this person will perform this action.

This may mean that there cannot be moral dilemmas of the form exemplified by (1), (2) and (3), and that determinism is incompatible with many claims about what we ought to do. It

\footnotetext{
${ }^{48}$ See, for example, Moore 1912, 102-15.
} 
certainly means that philosophers who want to argue that these things are not the case will have to do this without rejecting $(\mathrm{O}) .^{49}$

\section{References}

Audi, Robert. 2004. The Good in the Right: A Theory of Intuition and Intrinsic Value. Princeton: Princeton University Press.

Aune, Bruce. 1967. "Hypotheticals and 'Can': Another Look”. Analysis 27: 191-95.

Baier, Kurt. 1963. "Could and Would”. Analysis 23 (supplement): 20-29.

Blum, Alex. 2000. "The Kantian versus Frankfurt". Analysis 60: 287-88.

Brink, David. 1994. "Moral Conflict and Its Structure”. Philosophical Review 103: 215-47.

Broad, C. D. 1952. "Determinism, Indeterminism, and Libertarianism". In his Ethics and the History of Philosophy. London: Routledge.

Broome, John. 2004. "Reasons”. In Philip Pettit, Samuel Scheffler, Michael Smith and Jay Wallace, eds., Reason and Value: Essays on the Moral Philosophy of Joseph Raz. Oxford: Oxford University Press.

Chisholm, Roderick M. 1966. "Freedom and Action". In Keith Lehrer, ed., Freedom and Determinism. New York: Random House.

Copp, David. 1997. "Defending the Principle of Alternate Possibilities: Blameworthiness and Moral Responsibility". Noûs 31: 441-56.

Dancy, Jonathan. 2004a. "Enticing Reasons”. In Philip Pettit, Samuel Scheffler, Michael Smith and Jay Wallace, eds., Reason and Value: Essays on the Moral Philosophy of Joseph Raz. Oxford: Oxford University Press.

${ }^{49}$ For comments on previous versions of this paper, I would like to thank Stephen Butterfill, Ben Colburn, Roger Crisp, Jonathan Dancy, Daniel Elstein, Hallvard Lillehammer, Neil Sinclair, several anonymous referees, and audiences at the Cambridge University Moral Sciences Club, the Joint Session of the Aristotelian Society and the Mind Association at the University of Kent at Canterbury, and the University of Reading. 
Dancy, Jonathan. 2004b. Ethics Without Principles. Oxford: Oxford University Press.

Donagan, Alan. 1984. “Consistency in Rationalist Moral Systems”. Journal of Philosophy 81: 291-309. Reprinted in Gowans 1987.

Ekstrom, Laura Waddell. 2000. Free Will. Boulder: Westview Press.

Ewing, A. C. 1964. "May Can-Statements Be Analysed Deterministically?” Proceedings of the Aristotelian Society 64: 157-76.

Feldman, Fred. 1986. Doing the Best We Can. Dordrecht: Reidel.

Fischer, John Martin. 1994. The Metaphysics of Free Will. Oxford: Blackwell.

Fischer, John Martin. 1999. "Recent Work on Moral Responsibility”. Ethics 110: 93-139.

Fischer, John Martin. 2003. “'Ought-Implies-Can’, Causal Determinism and Moral Responsibility". Analysis 63: 244-50.

Frankena, William K. 1950. “Obligation and Ability”. In Max Black, ed., Philosophical Analysis. Ithaca: Cornell University Press.

Frankfurt, Harry. 1969. “Alternate Possibilities and Moral Responsibility”. Reprinted in his The Importance of What We Care About. Cambridge: Cambridge University Press, 1988.

Frankfurt, Harry. 1983. "What We Are Morally Responsible For". Reprinted in his The Importance of What We Care About. Cambridge: Cambridge University Press, 1988.

Gowans, Christopher, ed. 1987. Moral Dilemmas. Oxford: Oxford University Press.

Haji, Ishtiyaque. 1998. Moral Appraisability: Puzzles, Proposals, and Perplexities. New York: Oxford University Press.

Haji, Ishtiyaque. 2002. Deontic Morality and Control. Cambridge: Cambridge University Press.

Hare, R. M. 1963. Freedom and Reason. Oxford: Clarendon Press.

Harman, Gilbert. 2000. Explaining Value and Other Essays in Moral Philosophy. Oxford: Clarendon Press.

Hobbes, Thomas. 1651. Leviathan. Edited by Richard Tuck. Cambridge: Cambridge University Press, 1996.

Humberstone, I. L. 1971. "Two Sorts of 'Ought”". Analysis 32: 8-14.

Kane, Robert. 1985. Free Will and Values. Albany: State University of New York Press.

Kane, Robert. 1996. The Significance of Free Will. Oxford: Oxford University Press. 
Kant, Immanuel. 1781/87. Critique of Pure Reason. Translated by Paul Guyer and Allen W. Wood. Cambridge: Cambridge University Press, 1999.

Kant, Immanuel. 1788. Critique of Practical Reason. Translated by Mary J. Gregor. In The Cambridge Edition of the Works of Immanuel Kant: Practical Philosophy. Cambridge: Cambridge University Press, 1996.

Kant, Immanuel. 1793. "On the Common Saying: That may be correct in theory, but it is of no use in practice". Translated by Mary J. Gregor. In The Cambridge Edition of the Works of Immanuel Kant: Practical Philosophy. Cambridge: Cambridge University Press, 1996.

Kekes, John. 1984. “'Ought Implies Can’ and Two Kinds of Morality”. Philosophical Quarterly 34: 459-467.

Kramer, Matthew. 2004. Where Law and Morality Meet. Oxford: Oxford University Press. Lamb, James. 1993. "Evaluative Compatibilism and the Principle of Alternate Possibilities". Journal of Philosophy 90: 517-27.

Lehrer, Keith. 1960. “Can We Know That We Have Free Will By Introspection?” Journal of Philosophy 57: 145-57.

Lehrer, Keith. 1966. “An Empirical Disproof of Determinism?” In Keith Lehrer, ed., Freedom and Determinism. New York: Random House.

Lehrer, Keith. 1968. "Cans Without Ifs”. Analysis 29: 29-32.

Lemmon, E. J. 1962. "Moral Dilemmas”. Philosophical Review 71: 139-58. Reprinted in Gowans 1987.

Marcus, Ruth Barcan. 1980. "Moral Dilemmas and Consistency”. Journal of Philosophy 77: 121-36. Reprinted in Gowans 1987.

Matthews, Gareth B. 1998. “Augustine”. In Edward Craig, ed., The Routledge Encyclopedia of Philosophy. London: Routledge.

McConnell, Terrance C. 1978. "Moral Dilemmas and Consistency in Ethics". Canadian Journal of Philosophy 8: 269-87. Reprinted in Gowans 1987.

Mele, Alfred R., and David Robb. 1998. "Rescuing Frankfurt-Style Cases". Philosophical Review 107: 97-112.

Moore, G. E. 1912. Ethics. Oxford: Oxford University Press, 1966.

Moore, G. E. 1922. Philosophical Studies. London: Routledge. 
Parfit, Derek. 1997. "Reasons and Motivation". Proceedings of the Aristotelian Society, supplementary volume 71: 99-130.

Pereboom, Derk. 2001. Living Without Free Will. Cambridge: Cambridge University Press.

Pietroski, Paul M. 1993. "Prima Facie Obligations, Ceteris Paribus Laws in Moral Theory". Ethics 103: 489-515.

Railton, Peter. 1996. “The Diversity of Moral Dilemma”. In H. E. Mason, ed., Moral Dilemmas and Moral Theory. Oxford: Oxford University Press.

Raz, Joseph. 1990. Practical Reason and Norms (second edition). Oxford: Oxford University Press.

Raz, Joseph. 1999. Engaging Reason. Oxford: Oxford University Press.

Saka, Paul. 2000. “Ought Does Not Imply Can”. American Philosophical Quarterly 37: 93105.

Scanlon, T. M. 1998. What We Owe To Each Other. Cambridge, Mass.: Harvard University Press.

Schnall, Ira M. 2001. “The Principle of Alternate Possibilities and 'Ought' Implies 'Can'”. Analysis 61: 335-40.

Sidgwick, Henry. 1907. The Methods of Ethics. Indianapolis: Hackett, 1981.

Sinnott-Armstrong, Walter. 1984. “'Ought' Conversationally Implies 'Can””. Philosophical Review 93: 249-61.

Sinnott-Armstrong, Walter. 1985. "'Ought to Have' and 'Could Have'”. Analysis 45: 44-48.

Stern, Robert. 2004. “Does 'Ought' Imply 'Can'? And Did Kant Think It Does?” Utilitas 16: $42-61$.

Stocker, Michael. 1971. “'Ought' and 'Can”. Australasian Journal of Philosophy 49: 303316.

Streumer, Bart. 2003. 'Does 'Ought' Conversationally Implicate 'Can'?” European Journal of Philosophy 11: 219-28.

Streumer, Bart. 2005. "Semi-Global Consequentialism and Blameless Wrongdoing: Reply to Brown". Utilitas 17: 226-30.

Taylor, Richard. 1962. "Fatalism". Philosophical Review 71: 56-66.

van Fraassen, Bas C. 1973. "Values and the Heart's Command". Journal of Philosophy 70: 519. Reprinted in Gowans 1987. 
van Inwagen, Peter. 1978. “Ability and Responsibility”. Philosophical Review 87: 201-24. van Inwagen, Peter. 1983. An Essay on Free Will. Oxford: Clarendon Press.

White, Alan R. 1975. Modal Thinking. Oxford: Blackwell.

Widerker, David. 1991. 'Frankfurt on 'Ought' Implies 'Can' and Alternative Possibilities”. Analysis 51: 222-224.

Widerker, David. 1995. “Libertarianism and Frankfurt's Attack on the Principle of Alternative Possibilities". Philosophical Review 104: 247-61.

Widerker, David. 2000. "Frankfurt's Attack on the Principle of Alternative Possibilities: A Further Look". Philosophical Perspectives 14: 181-201.

Williams, Bernard. 1973. "Ethical Consistency". In his Problems of the Self. Cambridge: Cambridge University Press. Reprinted in Gowans 1987.

Williams, Bernard. 1981. “Ought and Moral Obligation”. In his Moral Luck. Cambridge: Cambridge University Press.

Yaffe, Gideon. 1999. “'Ought' Implies 'Can' and the Principle of Alternate Possibilities”. Analysis 59: 218-222.

Zimmerman, Michael. 1996. The Concept of Moral Obligation. Cambridge: Cambridge University Press. 